\title{
Progressive multifocal leukoencephalopathy, myelodysplastic syndrome type II and prostatic carcinoma
}

\author{
P. BARBER \\ M.B., Ch.B. \\ J. A. MORRIS \\ M.A., M.R.C.Path.
}

\author{
D. W. GORST \\ M.R.C.P., M.R.C.Path. \\ J. D. PEARSON \\ M.B., M.R.C.P.
}

Lancaster Moor Hospital and Royal Lancaster Infirmary, Lancaster

\begin{abstract}
Summary
A case is described of progressive multifocal leukoencephalopathy (PML) occurring in a man with myelodysplastic syndrome type II (MDS II) and prostatic carcinoma. This is the first case, to our knowledge, of the association of PML with MDS II.
\end{abstract}

KEY WORDS: hemiplegia, phenylbutazone, myelodysplasia, multifocal leukoencephalopathy, prostatic carcinoma.

\section{Introduction}

Progressive multifocal leukoencephalopathy (PML) is a rare progressive demyelinating disease which is difficult to diagnose in life without a high index of suspicion. Thus it is important to delineate the conditions with which it is associated. There are reports of its association with widespread carcinomatosis but not of its association with myelodysplastic syndrome II (MDS II).

\section{Case report}

An 82-year-old retired fishmonger was referred with a 2-week history of gradual onset of left-sided weakness. He had become incontinent of urine and forgetful. His past medical history was unremarkable apart from pain from a right osteo-arthritic hip for which he took phenylbutazone. General examination showed fast atrial fibrillation (110 per min) and blood pressure $150 / 90 \mathrm{mmHg}$. He was not in heart failure. Rectal examination revealed a firm, enlarged prostate gland. He had a left hemiparesis with weakness more marked in the leg than the arm. Mental testing revealed him to be fully orientated and to have a good recent memory. He was mildly anaemic (haemoglobin $9.6 \mathrm{~g} / \mathrm{dl}$ ) with normal red cell indices, the erythrocyte sedimentation rate was $46 \mathrm{~mm}$. The serum acid phosphatase was high at $31.0 \mathrm{u} /$ litre and he was folate deficient with serum levels on two occasions of 0.2 and $1.0 \mu \mathrm{g} /$ litre $(\mathrm{ng} / \mathrm{ml})$. Serum ferritin was in the normal range at $293 \mu \mathrm{g} / \mathrm{litre}$. A marrow aspirate from the iliac spine showed a hypercellular marrow with marked dyserythropoiesis, increased reticuloendothelial iron and numerous tight ringed sideroblasts. Following admission, his hemiparesis worsened and he developed marked anosognosia, a left apraxia and frontal signs including a loss of inhibition. There was no papilloedema. His electroencephalogram was abnormal showing asymmetry between the two hemispheres with slow frequencies and focal delta activity in the right anterior region. There was no response to dexamethasone. He died 2 months after admission. Postmortem examination revealed multiple large areas of demyelination of the white matter of both cerebral hemispheres. Histologically these showed the classical features of PML, with extensive demyelination, degeneration of oligodendrocytes and enlargement and bizarre transformation of astrocyte nuclei (Fig. 1). In addition, there was a moderately differentiated adenocarcinoma of the prostate which had invaded lymph nodes within the pelvis but had not extended beyond the pelvis.

\section{Discussion}

PML is a rare, progressive disease of the central nervous system (CNS) thought to be induced by papova viruses and occurring predominantly in immunocompromised patients. It has been reported in patients with lymphoproliferative and myeloproliferative neoplasms, carcinomatosis, chronic granulomatous disease but only occasionally in patients with no proven chronic disorder (Richardson, 1974). Papova viruses have been identified in the CNS lesions by electron microscopy and fluorescent antibody techniques and isolated from the lesions in tissue culture. (Editorial, 1972; Narayan et al., 1973). 


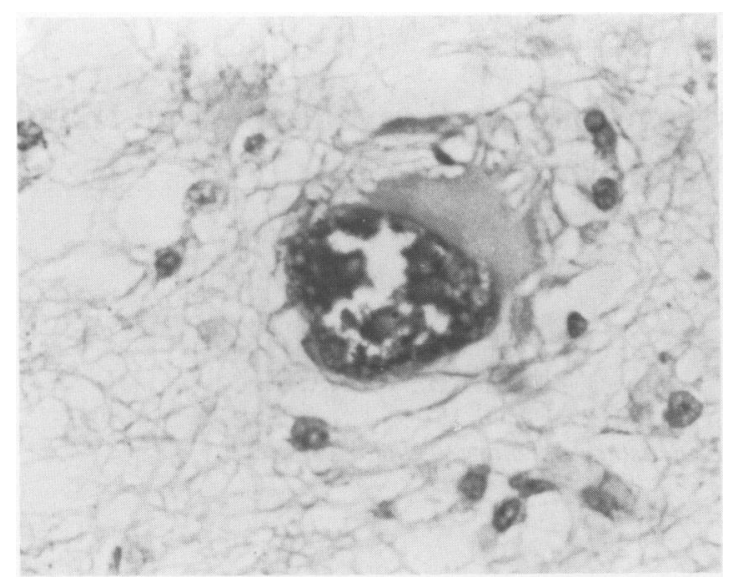

Fig. 1. PML: Neuroglial cell with a grossly enlarged nucleus surrounded by cells of normal size, H.E., $\times 512$.

MDS II gives a chronic refractory anaemia with dyserythropoiesis and pathological sideroblastic change in the marrow. Growing interest in the syndromes of marrow dysplasia and pre-leukaemia has led to a recent classification by the French/American/British Group (Bennett et al., 1982). This form of acquired sideroblastic anaemia has been described in association with malignancy without the bone marrow but is most often a primary disorder which may be pre-leukaemic. The one published case (Allergranza et al., 1981) of PML in pre-leukaemia does not give sufficient haematological detail decide exactly the nature of marrow dysplasia. There was very rapid evolution to a florid leukaemic state which is more suggestive of a smouldering leukaem than myelodysplasia.

\section{Acknowledgments}

We thank Professor P. O. Yates of the University Departmentof Pathology in Manchester for reviewing the histology and Dr J.CE. McIver of Manchester Royal Infirmary for reviewing the haemarylogy.

\section{References}

Allegranza, A., Boeri, R., Mariani, C., Sghirlanzoni, A.尹 Peluchetti, N. (1981) A case of progressive multifocal leukoe cephalopathy in preleukaemic syndrome. Acta Neuropathology (Berlin), VII (Suppl.), 192.

BennetT, J.M., Catovsky, D., Daniel, M.T., Flandrin, o Galton, D.A.G., Gralnick, H.R. \& Sultan, C. (1982) Pro posals for the classification of the myelodysplastic syndromed. British Journal of Haematology, 51, 189.

EDITORIAL (1972) Papovaviruses and human disease. British Medical Journal, 3, 540.

Narayan, O., Peney, J.B., Johnson, R.T., Herndon, R.M. T WEINER, L.P (1973) Etiology of progressive multifocal leukoenecphalopathy: identification of papovaviruses. New England Journal of Medicine, 289, 1278.

RICHARDSON, E.P. (1974) Our evolving understanding of pregressive multifocal leukoencephalopathy. Annals of the New Academy Science, 230, 358.

(Accepted 16 March 1983) 